\title{
Association of breast cancer with MRI background parenchymal enhancement: the IMAGINE case-control study
}

Gordon P. Watt ${ }^{1 *+} \mathbb{D}$, Janice Sung ${ }^{2 \dagger}$, Elizabeth A. Morris ${ }^{2}$, Saundra S. Buys ${ }^{3}$, Angela R. Bradbury ${ }^{4}$, Jennifer D. Brooks ${ }^{5}$, Emily F. Conant ${ }^{6}$, Susan P. Weinstein ${ }^{6}$, Despina Kontos ${ }^{6}$, Meghan Woods $^{1}$, Sarah V. Colonna ${ }^{3}$, Xiaolin Liang ${ }^{1}$, Matthew A. Stein ${ }^{3}$, Malcolm C. Pike ${ }^{1}$ and Jonine L. Bernstein ${ }^{1}$

\begin{abstract}
Background: Background parenchymal enhancement (BPE) on breast magnetic resonance imaging (MRI) may be associated with breast cancer risk, but previous studies of the association are equivocal and limited by incomplete blinding of BPE assessment. In this study, we evaluated the association between BPE and breast cancer based on fully blinded assessments of BPE in the unaffected breast.
\end{abstract}

Methods: The Imaging and Epidemiology (IMAGINE) study is a multicenter breast cancer case-control study of women receiving diagnostic, screening, or follow-up breast MRI, recruited from three comprehensive cancer centers in the USA. Cases had a first diagnosis of unilateral breast cancer and controls had no history of or current breast cancer. A single board-certified breast radiologist with 12 years' experience, blinded to case-control status and clinical information, assessed the unaffected breast for BPE without view of the affected breast of cases (or the corresponding breast laterality of controls). The association between BPE and breast cancer was estimated by multivariable logistic regression separately for premenopausal and postmenopausal women.

Results: The analytic dataset included 835 cases and 963 controls. Adjusting for fibroglandular tissue (breast density), age, race/ethnicity, BMI, parity, family history of breast cancer, BRCA1/BRCA2 mutations, and other confounders, moderate/marked BPE (vs minimal/mild BPE) was associated with breast cancer among premenopausal women [odds ratio (OR) $1.49,95 \% \mathrm{Cl} 1.05-2.11 ; p=0.02]$. Among postmenopausal women, mild/moderate/marked vs minimal BPE had a similar, but statistically non-significant, association with breast cancer (OR 1.45, 95\% Cl 0.92-2.27; $p=0.1$ ).

Conclusions: BPE is associated with breast cancer in premenopausal women, and possibly postmenopausal women, after adjustment for breast density and confounders. Our results suggest that BPE should be evaluated alongside breast density for inclusion in models predicting breast cancer risk.

Keywords: Breast cancer, Background parenchymal enhancement, Magnetic resonance imaging, Risk factors, Casecontrol study

\footnotetext{
*Correspondence: wattg@mskcc.org

Portions of this work were previously presented as a poster at a postdoctoral

symposium at Memorial Sloan Kettering Cancer Center.

${ }^{\dagger}$ Gordon P. Watt and Janice Sung contributed equally to this work.

${ }^{1}$ Department of Epidemiology and Biostatistics, Memorial Sloan Kettering Cancer Center, 485 Lexington Ave., Second Floor, New York, NY 10017, USA

Full list of author information is available at the end of the article
}

(C) The Author(s). 2021 Open Access This article is licensed under a Creative Commons Attribution 4.0 International License, which permits use, sharing, adaptation, distribution and reproduction in any medium or format, as long as you give appropriate credit to the original author(s) and the source, provide a link to the Creative Commons licence, and indicate if changes were made. The images or other third party material in this article are included in the article's Creative Commons licence, unless indicated otherwise in a credit line to the material. If material is not included in the article's Creative Commons licence and your intended use is not permitted by statutory regulation or exceeds the permitted use, you will need to obtain permission directly from the copyright holder. To view a copy of this licence, visit http://creativecommons.org/licenses/by/4.0/ The Creative Commons Public Domain Dedication waiver (http://creativecommons.org/publicdomain/zero/1.0/) applies to the data made available in this article, unless otherwise stated in a credit line to the data. 


\section{Background}

One of the strongest known risk factors of breast cancer, breast density [i.e., the "amount" of fibroglandular tissue (FGT)], is assessed using mammography and has been successfully incorporated into models of breast cancer risk $[1,2]$. Breast density can also be estimated by assessing FGT on breast magnetic resonance imaging (MRI) [3]. After administration of the contrast agent during a breast MRI examination, FGT enhances to varying degrees, a phenomenon known as background parenchymal enhancement (BPE). In clinical practice, radiologists qualitatively categorize FGT as almost entirely fat, scattered, heterogeneous, or extreme, and BPE as minimal, mild, moderate, or marked, according to the Breast Imaging Reporting and Data System (BI-RADS) [4]. BPE differs widely between women and is sensitive to endogenous hormonal changes, particularly menopause [5-10], as well as exogenous factors, including menopausal hormone therapy, tamoxifen, aromatase inhibitors, radiation therapy, and chemotherapy [7, 11-13].

Previous studies have reported associations between BPE and breast cancer, with varying conclusions [1421]. Interpretation of these studies has been limited by (A) lack of blinding to the MRI of the affected breast of women with breast cancer; (B) lack of blinding to patient clinical characteristics and history; $(C)$ inter-reader variability in BPE assessment; and/or (D) no accounting for menopausal status, which strongly affects BPE. In contrast to these previous studies, the Imaging and Epidemiology (IMAGINE) study $(N=1798)$ employed a fully blinded and centralized approach to measure BPEwhich reduced bias, eliminated inter-observer variability, and improved internal validity-in order to accurately assess the magnitude of association between BPE and breast cancer. Most importantly, the study radiologist was blinded to all clinical characteristics and casecontrol status and was able to visualize only one breast of each MRI series: the unaffected breast for cases and a corresponding breast for controls.

If $\mathrm{BPE}$ is confirmed as a reproducible marker of breast cancer risk, it will improve risk prediction and permit further personalization of breast cancer screening.

\section{Methods}

The IMAGINE study is a multicenter, hospital-based, case-control study that recruited participants between November 2014 and September 2017. The source population included women aged $\geq 21$ to $<70$ years with a bilateral breast MRI between 2010 and 2017 available at breast MRI clinics at three National Cancer Institutedesignated comprehensive cancer centers: Memorial Sloan Kettering Cancer Center in New York, New York (MSK); Perelman Center for Advanced Medicine at the University of Pennsylvania in Philadelphia, Pennsylvania; and Huntsman Cancer Institute at the University of Utah in Salt Lake City, Utah. Indication for MRI was not captured and included women undergoing follow-up for a suspicious lesion, referrals for treatment or second opinions at one of the IMAGINE recruitment sites, diagnostic workup, or annual screening MRI for high-risk women. Potentially eligible participants were identified both prospectively (approached at the time of their breast MRI) and retrospectively (contacted after their breast MRI). Potential breast cancer cases received a diagnosis on or after January 1, 2010, of a unilateral invasive breast cancer and/or a unilateral ductal carcinoma in situ (DCIS) and received a screening or diagnostic bilateral breast MRI prior to radiation therapy or any systemic therapy. Potential controls received a screening or follow-up bilateral breast MRI and had no history of invasive cancer or DCIS at the time of or within 6 months after the MRI. Cases and controls were ineligible if, at the time of MRI, they (a) had a previous diagnosis of any invasive cancer; (b) had a history of prophylactic mastectomy; (c) had a history of prepectoral breast implants; (d) had a history of breast reduction surgery; (e) had taken tamoxifen, aromatase inhibitors, or raloxifene in the preceding three months; (f) were pregnant or breast feeding in the preceding six months; or (g) were unable to speak and read English. Women were not excluded due to history of breast biopsy or fine needle aspiration. Timing of menstrual cycle at MRI date is not associated with BPE [22, 23] and was not recorded in this study. At all sites, the same multimodality recruitment approaches (in-person at breast MRI clinic, via mail, and via email) were used to contact potentially eligible women. The study was approved by the institutional review boards at each recruitment site.

After contacting potentially eligible women, participants provided informed consent and completed an epidemiological questionnaire to capture detailed family history of breast cancer, BRCA1 and BRCA2 testing history and mutation status, reproductive history, medical history, and demographic data. Study questionnaire data were managed using REDCap electronic data capture tools hosted at MSK [24, 25]. Study staff accessed participant medical records to confirm eligibility, abstract tumor characteristics of cases, and obtain MRI series. Final case-control status was determined 6 months after enrollment in the study to verify that women identified as controls did not develop an invasive cancer in the intervening period. Clinical MRIs were acquired using standard protocols for each institution, which included both axial and sagittal images using either 1.5- or 3Tesla coils.

Prior to MRI characterization, controls were individually matched 1:1 to cases by race/ethnicity, recruitment site, age at MRI (within 5 years), and menopausal status 
at MRI. However, in order to improve the efficiency of study recruitment, cases and controls were enrolled in the IMAGINE study prior to confirming a suitable match, resulting in a number of unmatched cases and controls. Each matched case-control MRI pair was included together in a batch of 20 MRIs to be read on the same day by a single board-certified breast radiologist with 12 years' experience (JS). For matched cases, study staff selected the unaffected breast for assessment of FGT and BPE. For matched controls, the laterality corresponding to that of the matched case was selected for assessment. For unmatched cases, the unaffected breast was assessed as usual and, for unmatched controls, the breast to be assessed was selected at random by study staff. The MRI series of the selected breast was provided to the study radiologist with the unselected breast obscured from view. The study radiologist was also blinded to case-control status and all clinical and demographic information. Following BI-RADS reporting guidelines, FGT was characterized as almost entirely fat, scattered, heterogeneous, or extreme using the T1-weighted nonfat-saturated series and BPE was estimated as minimal, mild, moderate, or marked using the T1-weighted fatsaturated sequence from the pre-contrast and the first post-contrast series along with the subtraction image [4]. Breast size was not estimated. The time from precontrast to the first post-contrast image may have varied slightly between institutions over the seven-year recruitment period, but the exact timing was not available. The study team also included repeat images for 130 women in selected batches of MRIs in order to assess the reproducibility of FGT and BPE by the study radiologist. The radiologist was aware of the study design but did not know which batches contained repeat images or how many repeats were included. We calculated Cohen's weighted kappa statistics and 95\% CIs for each measure [26].

All analyses were stratified by menopausal status, as BPE is known to decline sharply after menopause [8], with most postmenopausal women having minimal BPE [5]. Postmenopausal women included those whose menstrual cycles had stopped naturally at least 12 months prior to the MRI, those with a history of bilateral oophorectomy, and those who reported being postmenopausal without further details. In addition, we categorized women with a history of simple hysterectomy who were 50 years or older at time of the MRI as postmenopausal. The remaining women were considered premenopausal.

Multivariable conditional logistic regression models were used to estimate the association between BPE and breast cancer, separately for premenopausal and postmenopausal women. For premenopausal women, we adjusted for FGT (heterogeneous/extreme vs fatty/scattered), history of simple hysterectomy (yes vs no), BMI $\left(<25, \geq 25\right.$ and $\left.<30, \geq 30 \mathrm{~kg} / \mathrm{m}^{2}\right)$, parity (nulliparous vs 1,2 , or 3 or more live births), as well as high-risk indications for breast cancer: 1st-degree female family history or 1st- or 2nd-degree male family history of breast cancer (yes vs no), BRCA1 and BRCA2 testing history and presence of BRCA1 or BRCA2 mutations (not tested vs positive vs negative), history of lobular carcinoma in situ (LCIS; yes vs no), and history of benign breast disease. The adjustment for high-risk indications accounts for the differing distribution of risk factors between controls, who were primarily high-risk women undergoing screening MRI, and cases, who represented a more average breast cancer risk population. We further accounted for the matched study design by conditioning the multivariable models on matching criteria: race/ethnicity (non-Hispanic White vs other), recruitment site, and age at MRI (5-year categories). The adjustment for matching variables controls for selection bias inherent in matched case-control studies [27]. Models of postmenopausal women were further adjusted for history of bilateral oophorectomy (yes vs no). In an exploratory analysis, based on a previous study reporting an association between reductions in adipose tissue and BPE [28], BMI-stratified models (BMI $<25$ vs BMI $\geq 25$ ) were estimated to evaluate effect modification by BMI.

Among cases, we evaluated the association of BPE (in the unaffected breast) with the patient's tumor characteristics: hormone (estrogen and progesterone) receptors, human epidermal growth factor 2 (HER2) expression, histological subtype (ductal, lobular, mixed, or other), and stage. In multivariable logistic regression models separately for premenopausal and postmenopausal women, we regressed BPE on these factors with additional adjustment for FGT, BMI, age, recruitment site, and race/ethnicity. All analysis was conducted in $\mathrm{R}$ version 3.5.1 [28]. Two-sided statistical significance was set at $5 \%$.

\section{Results}

Among 13,960 women with bilateral contrast-enhanced breast MRI at one of the recruitment sites between 2010 and 2017, 9021 were ineligible (64\% were ineligible due to previous cancer diagnosis) and 343 refused (102 confirmed cases and 64 confirmed controls, others not assigned). There were 2106 women who consented, completed the epidemiological questionnaire, and provided access to medical records and MRI series. Twentynine women (4 confirmed cases and 10 confirmed controls, others not assigned) ultimately withdrew from the study. We excluded 39 cases who had DCIS without invasive cancer and 269 women with MRI series that were either corrupted or deemed inadequate for accurate assessment of FGT and BPE by the study radiologist, leaving a total of 1798 women (835 cases 963 controls) in 
the analytic dataset with complete MRI assessments for analysis. In Fig. 1, we provide additional details of study recruitment. The median time between MRI and questionnaire was 10 days [interquartile range (IQR) 0-240] for controls and 233 days (IQR 41-979) for cases.

Table 1 displays the characteristics of the study population. Control women were more likely than cases to have a family history of breast cancer, $B R C A 1$ and $B R C A 2$ mutations, a history of LCIS and a history of benign breast disease. Therefore, in the multivariable models, we adjusted for these differences between cases and controls. Among cases, tumors were primarily ductal and confined to the breast. There were 168 participants (20 cases and 148 controls) without a match for MRI assessment. Women without a match were more likely to be recruited from MSK and were younger at the time of their MRI but otherwise did not differ notably from the matched women (Supplementary Table 1).

The distribution of BPE differed by menopausal status (Table 2): $18 \%$ of premenopausal women had minimal BPE, while $44 \%$ of postmenopausal women had minimal BPE. There was no detectable correlation between BPE and FGT categories $(r=0.03, p=0.2)$. Among the subset with repeat measurements $(n=130)$, we found good agreement for BPE (weighted $\kappa=0.73$, 95\% CI 0.650.82 ) and FGT (weighted $\kappa=0.83,95 \%$ CI $0 .-76-0.90$ ).

In Table 3, we present the adjusted associations between $\mathrm{BPE}$ and breast cancer in multivariable logistic regression.
Analysis using all four levels of BPE as the independent variable revealed a non-linear association between $\mathrm{BPE}$ and breast cancer risk, with large confidence intervals for the moderate/marked estimates in postmenopausal women. Therefore, we dichotomized BPE differentially for pre- and postmenopausal women based on previous studies and justified by the distribution of the data. Among premenopausal women, moderate/marked BPE was statistically significantly associated with breast cancer $(\mathrm{OR}=$ 1.49 , 95\% CI $1.05-2.11 ; p=0.02)$. In postmenopausal women, mild/moderate/marked BPE had a suggestive but non-significant association with breast cancer $(\mathrm{OR}=1.45$, 95\% CI 0.92-2.27; $p=0.10$ ). A multiplicative interaction term between BPE and FGT did not improve the model fit for premenopausal women (likelihood ratio test $p=0.8$ ) or postmenopausal women $(p=0.9)$. In Table 3 , we also provide results from multivariable models stratified by BMI $(<25$ vs $\geq 25)$. Among premenopausal women, the OR for moderate/marked BPE appeared to be higher among women with BMI $\geq 25$ (OR 1.86, 95\% CI 1.03-3.37; $p=$ 0.04) compared to women with BMI $<25$ (OR 1.32, 95\% CI $0.84-2.03 ; p=0.2$ ). A similar pattern was observed for postmenopausal women (BMI $\geq 25$ : OR $2.20,95 \% \mathrm{CI}$ 1.02-4.71, $p=0.04$; BMI < 25: OR 1.06, 95\% CI 0.58-1.96, $p=0.8$ ). Overall, BMI was associated with BPE, with $34 \%$ of women with $\mathrm{BMI} \geq 25$ having moderate/marked BPE compared to $25 \%$ of women with BMI $<25(p<0.001)$.

In sensitivity analyses, we repeated the primary analysis restricting to non-Hispanic White women and

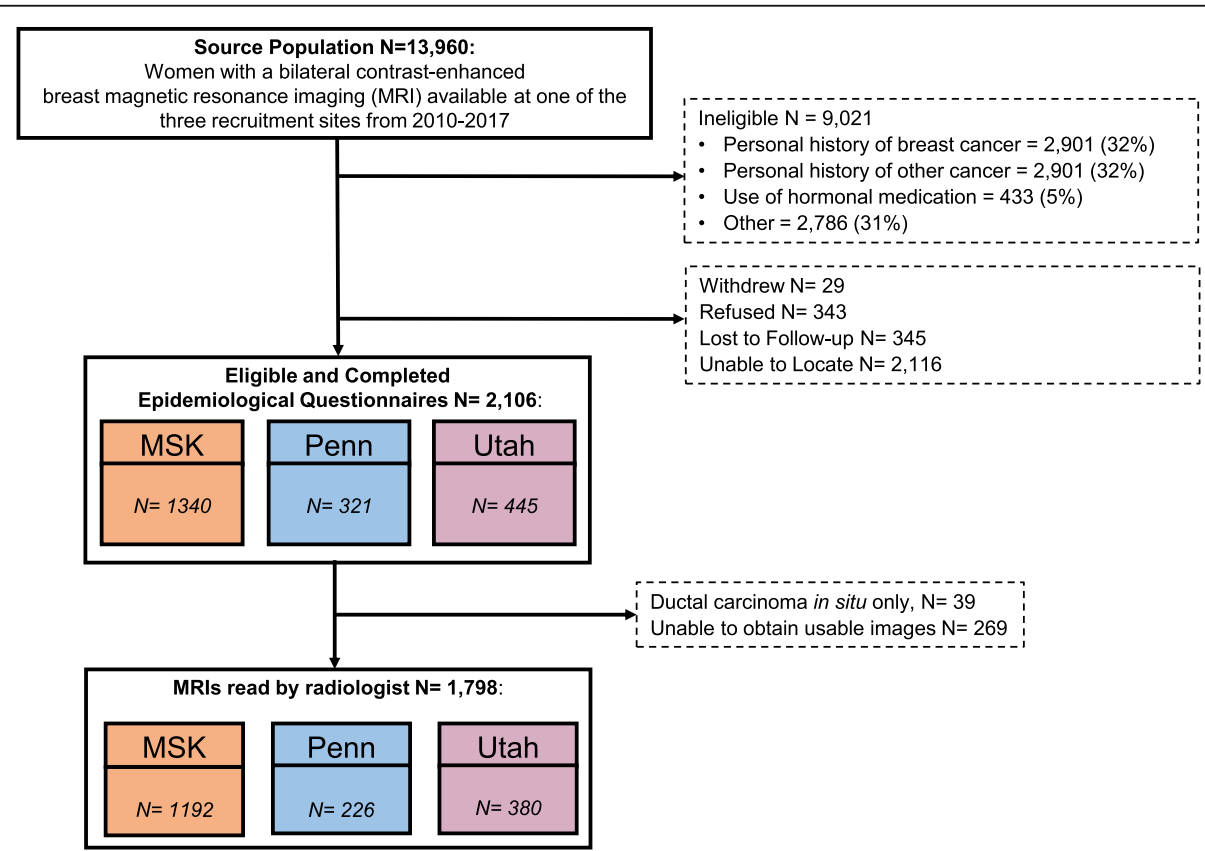

Fig. 1 Participants in the IMAGINE study were recruited from women undergoing breast MRI from three National Cancer Institute-designated Comprehensive Cancer Centers between 2010 and 2017. The final analytic sample included 1798 women with a valid assessment by a single board-certified radiologist 
Table 1 Characteristics of the IMAGINE study participants

\begin{tabular}{|c|c|c|c|c|}
\hline & \multicolumn{2}{|c|}{ Premenopausal women } & \multicolumn{2}{|c|}{ Postmenopausal women } \\
\hline & Cases & Controls & Cases & Controls \\
\hline & $N=553$ & $N=623$ & $N=282$ & $N=340$ \\
\hline Age, median (25th, 75th percentile) & $45(40,48)$ & $42(37,47)$ & $59(55,63)$ & $57(53,62)$ \\
\hline \multicolumn{5}{|l|}{ Recruitment site } \\
\hline Memorial Sloan Kettering Cancer Center & $373(67 \%)$ & $431(69 \%)$ & $165(59 \%)$ & $223(66 \%)$ \\
\hline University of Pennsylvania Medical Center & $65(12 \%)$ & $67(11 \%)$ & $44(16 \%)$ & $50(15 \%)$ \\
\hline University of Utah Huntsman Cancer Institute & $115(21 \%)$ & $125(20 \%)$ & $73(26 \%)$ & $67(20 \%)$ \\
\hline \multicolumn{5}{|l|}{ Menopausal status and reason ${ }^{a}$} \\
\hline Premenopausal & $537(97 \%)$ & $597(96 \%)$ & & \\
\hline Premenopausal (simple hysterectomy) & $16(3 \%)$ & $26(4 \%)$ & & \\
\hline Postmenopausal (natural) & & & $212(75 \%)$ & $207(61 \%)$ \\
\hline Postmenopausal (oophorectomy) & & & $25(9 \%)$ & $93(27 \%)$ \\
\hline Postmenopausal (simple hysterectomy) & & & $38(13 \%)$ & $37(11 \%)$ \\
\hline Postmenopausal (reason unknown) & & & $7(3 \%)$ & $3(1 \%)$ \\
\hline \multicolumn{5}{|l|}{ Race/ethnicity } \\
\hline Non-Hispanic White & $451(81 \%)$ & $513(82 \%)$ & $227(80 \%)$ & $301(89 \%)$ \\
\hline Non-Hispanic Black & $31(6 \%)$ & $24(4 \%)$ & $17(6 \%)$ & $14(4 \%)$ \\
\hline Non-Hispanic Asian & $31(6 \%)$ & $26(4 \%)$ & $15(5 \%)$ & $10(3 \%)$ \\
\hline Non-Hispanic (another race) & $10(2 \%)$ & $16(3 \%)$ & $3(1 \%)$ & $3(1 \%)$ \\
\hline Hispanic (any race) & $30(5 \%)$ & $44(7 \%)$ & $20(8 \%)$ & $12(3 \%)$ \\
\hline \multicolumn{5}{|l|}{ Ever smoker } \\
\hline Never & $426(77 \%)$ & $485(78 \%)$ & $194(69 \%)$ & $254(75 \%)$ \\
\hline Ever & $127(23 \%)$ & $138(22 \%)$ & $88(31 \%)$ & $86(25 \%)$ \\
\hline \multicolumn{5}{|l|}{ Body mass index at time of $\mathbf{M R I}^{\mathrm{b}}\left(\mathrm{kg} / \mathrm{m}^{2}\right)$} \\
\hline$<25$ & $346(63 \%)$ & $400(64 \%)$ & $113(40 \%)$ & $208(61 \%)$ \\
\hline 25 to $<30$ & $121(22 \%)$ & $143(23 \%)$ & $96(34 \%)$ & $67(20 \%)$ \\
\hline$\geq 30$ & $85(15 \%)$ & $78(13 \%)$ & $73(26 \%)$ & $64(19 \%)$ \\
\hline Unknown & 1 & 2 & 0 & 1 \\
\hline \multicolumn{5}{|l|}{ Parity } \\
\hline 0 & $194(35 \%)$ & $230(37 \%)$ & $67(24 \%)$ & $83(24 \%)$ \\
\hline 1 & $89(15 \%)$ & $77(12 \%)$ & $49(17 \%)$ & $50(15 \%)$ \\
\hline $2+$ & $270(50 \%)$ & $316(51 \%)$ & $166(59 \%)$ & $197(61 \%)$ \\
\hline \multicolumn{5}{|l|}{ Family history of breast cancer ${ }^{c}$} \\
\hline No & $399(77 \%)$ & $210(34 \%)$ & $181(68 \%)$ & $103(31 \%)$ \\
\hline Yes & $116(23 \%)$ & $399(66 \%)$ & 85 (32\%) & $231(69 \%)$ \\
\hline Unknown (n) & 38 & 14 & 16 & 6 \\
\hline \multicolumn{5}{|l|}{ BRCA1 mutation ${ }^{d}$} \\
\hline Negative & $340(66 \%)$ & $202(33 \%)$ & $99(36 \%)$ & $127(39 \%)$ \\
\hline Positive & $9(1.7 \%)$ & $78(13 \%)$ & $4(1.4 \%)$ & $29(8.8 \%)$ \\
\hline Not tested & $166(32 \%)$ & $329(54 \%)$ & $173(63 \%)$ & $173(53 \%)$ \\
\hline Unknown & 38 & 14 & 6 & 11 \\
\hline \multicolumn{5}{|l|}{$B R C A 2$ mutation $^{\mathrm{d}}$} \\
\hline Negative & $340(66 \%)$ & $202(33 \%)$ & $95(34 \%)$ & $105(32 \%)$ \\
\hline Positive & $9(1.7 \%)$ & $78(13 \%)$ & $8(2.9 \%)$ & $51(16 \%)$ \\
\hline Not tested & $166(32 \%)$ & $329(54 \%)$ & $173(63 \%)$ & $173(53 \%)$ \\
\hline Unknown & 38 & 14 & 6 & 11 \\
\hline
\end{tabular}


Table 1 Characteristics of the IMAGINE study participants (Continued)

\begin{tabular}{|c|c|c|c|c|}
\hline & \multicolumn{2}{|c|}{ Premenopausal women } & \multicolumn{2}{|c|}{ Postmenopausal women } \\
\hline & Cases & Controls & Cases & Controls \\
\hline & $N=553$ & $N=623$ & $N=282$ & $N=340$ \\
\hline \multicolumn{5}{|c|}{ History of LCIS } \\
\hline No & $546(99 \%)$ & $584(94 \%)$ & $274(97 \%)$ & 302 (89\%) \\
\hline Yes & $7(1 \%)$ & $39(6 \%)$ & $8(3 \%)$ & $38(11 \%)$ \\
\hline \multicolumn{5}{|c|}{ History of benign breast disease } \\
\hline No & $443(80 \%)$ & $332(53 \%)$ & $210(74 \%)$ & $160(47 \%)$ \\
\hline Yes & $110(20 \%)$ & 291 (47\%) & 72 (26\%) & $180(53 \%)$ \\
\hline
\end{tabular}

MRIfibroglandular tissue

Almost entirely fat

Scattered FGT

\section{Characteristics of cases}

\section{Estrogen receptor}

Negative

Positive

Unknown

\section{Progesterone receptor}

Negative
Positive

Unknown

\section{HER2 expression}

Negative

Positive

Unknown

Triple-negative ${ }^{\mathrm{e}}$ subtype

No

Yes

Unknown

\section{Histology}

Ductal only

Mixed ductal/lobular

Lobular

Other

Unknown

\section{Stage}

$\begin{array}{lll}\text { Localized (breast only) } & 383(69 \%) & 214(76 \%) \\ \text { Regional (breast and regional nodes) } & 162(29 \%) & 62(22 \%) \\ \text { Distant } & 8(2 \%) & 4(2 \%) \\ \text { Unknown } & 0 & 2\end{array}$

Abbreviation: LCIS lobular carcinoma in situ, HER2 human epidermal growth factor 2

a"Premenopausal" refers to women who report continued menstrual cycles; "premenopausal (simple hysterectomy") refers to women whose menstrual cycles stopped after a simple hysterectomy and were under 50 years of age at time of MRl; "postmenopausal" refers to women who reported a natural stop of menstrual cycles; "postmenopausal (oophorectomy)" refers to women who underwent menopause due to a bilateral oophorectomy; "postmenopausal (simple hysterectomy) refers to women whose menstrual cycles stopped after a hysterectomy and were 50 years of age or older at the time of MRl; "postmenopausal (other)" refers to women whose menstrual cycle stopped due to medication or medical procedures or did not give further details ${ }^{\mathrm{b}}$ Calculated using self-reported height $(\mathrm{m})$ and weight $(\mathrm{kg})$

Includes 1 st-degree female relatives and any1st- or 2 nd-degree male relative

dSelf-reported by participants via structured questionnaire; variants of unknown significance were considered negative

'Triple-negative refers to women with tumors negative for estrogen receptors, progesterone receptors, and HER2 expression 
Table 2 Distribution of fibroglandular tissue and background parenchymal enhancement in premenopausal and postmenopausal women in the IMAGINE study

\begin{tabular}{lll}
\hline & Premenopausal $^{\mathbf{a}}$ women & Postmenopausal $^{\mathbf{a}}$ women \\
\hline Fibroglandular tissue $^{\mathbf{b}}$ & No. (\%) & No. (\%) \\
Almost entirely fat & $49(4.2 \%)$ & $78(13 \%)$ \\
Scattered & $225(19 \%)$ & $241(39 \%)$ \\
Heterogeneous & $598(51 \%)$ & $249(40 \%)$ \\
Extreme & $304(26 \%)$ & $54(8.7 \%)$ \\
Background parenchymal enhancement ${ }^{\mathbf{b}}$ & No. (\%) & No. (\%) \\
Minimal & $213(18 \%)$ & $275(44 \%)$ \\
Mild & $538(46 \%)$ & $265(43 \%)$ \\
Moderate & $306(26 \%)$ & $66(11 \%)$ \\
Marked & $119(10 \%)$ & $16(2.6 \%)$ \\
\hline
\end{tabular}

a"Premenopausal" refers to women who report continued menstrual cycles and women whose menstrual cycles stopped after a simple hysterectomy and were under 50 years of age at time of MRl; "postmenopausal" refers to women who reported a natural stop of menstrual cycles, women who underwent menopause due to a bilateral oophorectomy, women whose menstrual cycles stopped after a hysterectomy and were 50 years of age or older at the time of MRI, and women whose menstrual cycle stopped due to medication or medical procedures or did not give further details

${ }^{\mathrm{b}}$ Estimated for a single unaffected breast using BI-RADS (Breast Imaging - Reporting and Data System) guidelines by a single research radiologist blinded to casecontrol status, clinical characteristics, and medical history

found that the results were similar. Additionally, we restricted to matched case-control image pairs read in the same batch and estimated the association between breast cancer and BPE conditional on matched pair strata; these results were likewise not materially changed compared to the primary analysis. Finally, we excluded women who reported a history of simple hysterectomy, for whom it was not possible to determine the timing of menopause, and the results were also unchanged (Supplementary Table 2).

Restricting to cases, HER2 overexpression of the tumor was associated with BPE in the unaffected breast $(\mathrm{OR}=1.72,95 \%$ CI 1.07-2.76; $p=0.03)$ among premenopausal women, and hormone receptor (ER and/or PR) positivity was associated with BPE in the unaffected breast among postmenopausal women (OR 2.55, 95\% CI 1.31-5.34; $p=0.01$ ) (Table 4).

\section{Discussion}

Among premenopausal women, moderate or marked BPE was associated with a $49 \%$ increased odds of breast cancer relative to controls, which was robust in our sensitivity analyses. Among postmenopausal women, our results suggest that any BPE above minimal may be associated with increased risk of breast cancer. Additionally, our exploratory analysis stratified by BMI suggests possible effect modification of the association between BPE and breast cancer by BMI for both premenopausal and postmenopausal women. This finding is plausible given the possible relationship between visceral adipose tissue mass, endogenous hormone production, and BPE [28], but further study in distinct populations are needed to clarify the relationship between BMI, BPE, and breast cancer.
To our knowledge, there are eight previous studies that have tested the association between qualitative BPE and breast cancer (summarized in Table 5). Estimates of the BPE-breast cancer association were based on several different study designs of varying sizes $(N=26$ to $N=$ $4247)$ and ranged from a non-significant OR of $1.2(95 \%$ CI 0.5-3.3) [18] for comparing malignant to benign lesions, to a significant OR of 7.7 (95\% CI 1.5-39.5) for comparing breast cancer cases to cancer-free controls. Although most studies found a positive association between BPE and breast cancer, all had one or more limitations that precluded clear interpretation: (A) incomplete blinding of clinical characteristics including case/control status; (B) assessment of BPE with view of the affected breast; and/or (C) no accounting for menopausal status, which strongly affects BPE and the risk of breast cancer. Most importantly, assessment of BPE without blinding to the affected breast would likely bias the measures of association between BPE and breast cancer away from the null. For example, without blinding of the affected breast, Telegrafo et al. reported that 0/224 (0\%) of controls had marked BPE, compared to $72 / 162$ (44\%) of invasive cases, corresponding to an unadjusted odds ratios as high as 61 for moderate/marked vs minimal/mild BPE [19]. This distribution of BPE is not consistent with the larger and more representative data from the IMAGINE study or that of Arasu et al., which used pre-diagnosis MRI assessments from the Breast Cancer Surveillance Consortium [29]. The longitudinal study by Arasu et al. is well designed, using clinical BPE assessments among cancer-free women and following until a diagnosis of breast cancer, which ensured that the BPE assessment was not biased by presence of breast cancer. Inter-observer variability of $\mathrm{BPE}$ 
Table 3 Adjusted association between BPE and breast cancer in the IMAGINE study

\begin{tabular}{|c|c|c|c|c|}
\hline \multicolumn{5}{|l|}{ Premenopausal women } \\
\hline BPE classification ${ }^{a}$ & Cases & Controls & $\mathrm{OR}^{\mathrm{b}}$ & $95 \% \mathrm{Cl}$ \\
\hline 4-level BPE & $N(\%)$ & $N(\%)$ & & \\
\hline Minimal & $84(18 \%)$ & 107 (18\%) & Reference & \\
\hline Mild & $206(43 \%)$ & $287(48 \%)$ & 1.00 & $0.63-1.58$ \\
\hline Moderate & $138(29 \%)$ & $137(23 \%)$ & 1.72 & $1.03-2.88$ \\
\hline Marked & 49 (10\%) & $62(10 \%)$ & 1.00 & $0.51-1.94$ \\
\hline \multicolumn{5}{|l|}{ Dichotomous BPE } \\
\hline Minimal/mild BPE ${ }^{c}$ & $290(61 \%)$ & $394(66 \%)$ & Reference & \\
\hline Moderate/marked BPE & 187 (39\%) & $199(34 \%)$ & 1.49 & $1.05-2.11$ \\
\hline \multicolumn{5}{|l|}{ Women with $\mathrm{BMI}<25^{\mathrm{d}}$} \\
\hline Minimal/mild BPE & 197 (65\%) & $266(70 \%)$ & Reference & \\
\hline Moderate/marked BPE & $106(35 \%)$ & $112(30 \%)$ & 1.31 & $0.84-2.03$ \\
\hline \multicolumn{5}{|l|}{ Women with $\mathrm{BMI} \geq 25$} \\
\hline Minimal/mild BPE & $93(53 \%)$ & $128(60 \%)$ & Reference & \\
\hline Moderate/marked BPE & $81(47 \%)$ & 87 (40\%) & 1.86 & $1.03-3.37$ \\
\hline \multicolumn{5}{|l|}{ Postmenopausal women } \\
\hline BPE classification & Cases & Controls & $O R^{a}$ & $95 \% \mathrm{Cl}$ \\
\hline Minimal & $94(36 \%)$ & $162(50 \%)$ & Reference & \\
\hline Mild & $125(48 \%)$ & $124(39 \%)$ & 1.42 & $0.89-2.28$ \\
\hline Moderate & $31(12 \%)$ & $30(9 \%)$ & 1.64 & $0.75-3.59$ \\
\hline Marked & $10(4 \%)$ & $6(2 \%)$ & 1.32 & $0.38-4.55$ \\
\hline \multicolumn{5}{|l|}{ Dichotomous BPE } \\
\hline Minimal $B P E^{C}$ & $94(36 \%)$ & $162(50 \%)$ & Reference & \\
\hline Mild/moderate/marked BPE & $166(64 \%)$ & $160(50 \%)$ & 1.45 & $0.92-2.27$ \\
\hline \multicolumn{5}{|l|}{ Women with $\mathrm{BMI}<25$} \\
\hline Minimal BPE & $56(52 \%)$ & $116(57 \%)$ & Reference & \\
\hline Mild/moderate/marked BPE & $52(48 \%)$ & $86(43 \%)$ & 1.06 & $0.58-1.96$ \\
\hline \multicolumn{5}{|l|}{ Women with BMI $\geq 25$} \\
\hline Minimal BPE & $38(25 \%)$ & $46(38 \%)$ & Reference & \\
\hline Mild/moderate/marked BPE & $114(75 \%)$ & 74 (62\%) & 2.20 & $1.02-4.71$ \\
\hline
\end{tabular}

Abbreviations: $O R$ odds ratio, $C l$ confidence interval, $B M I$ body mass index

${ }^{\text {a}}$ Estimated for a single unaffected breast using BI-RADS (Breast Imaging - Reporting and Data System) guidelines by a single research radiologist blinded to casecontrol status, clinical characteristics, and medical history

${ }^{\mathrm{b}}$ ORs are estimated in a multivariable conditional logistic regression model with adjustment for FGT (heterogeneous/dense vs fatty/scattered); history of simple hysterectomy; BMI $(<25, \geq 25$ and $<30, \geq 30 \mathrm{~kg} / \mathrm{m} \neg 2)$; parity; 1 st-degree female family history or 1st- or 2nd-degree male family history of breast cancer; BRCA testing history; presence of BRCA mutations; history of lobular carcinoma in situ (LCIS); history of benign breast disease; and conditioned on matching criteria: race/ethnicity (non-Hispanic White vs other), recruitment site, and age at MRI (5-year categories)

${ }^{c}$ Parameterization of BPE differs for premenopausal and postmenopausal women to capture differing distributions of BPE in these groups

${ }^{\mathrm{d}}$ Models stratified by BMI at the time of MRI

assessment in the study by Arasu et al. adds uncertainty into the effect of the association between BPE and breast cancer, but also more closely represents current clinical practice. On the other hand, our single reader approach proved to be reliable and eliminated inter-observer variability, providing strong internal validity to estimate the strength of association between BPE and breast cancer. Our measures of association, although elevated, were more modest than previous work. It is plausible that complete blinding of MRI assessment reduced bias in $\mathrm{BPE}$ assessment and thereby attenuated the measure of association relative to previous unblinded studies.

There is a biologically plausible relationship between increased BPE and breast cancer. A previous histopathological study demonstrated that elevated BPE was associated with greater microvascular concentration and 
Table 4 The association between BPE and tumor characteristics among women with breast cancer in the IMAGINE study

\begin{tabular}{|c|c|c|c|c|}
\hline \multicolumn{5}{|l|}{ Premenopausal cases } \\
\hline Tumor characteristic & Minimal/mild BPE & Moderate/marked BPE ${ }^{\mathrm{a}}$ & $O R^{b}$ & $95 \% \mathrm{Cl}$ \\
\hline \multicolumn{5}{|c|}{ Hormone receptor status ${ }^{c}$} \\
\hline Negative & $48(15 \%)$ & $33(16 \%)$ & Reference & \\
\hline Positive & $277(85 \%)$ & $178(84 \%)$ & 1.00 & $0.59-1.68$ \\
\hline \multicolumn{5}{|l|}{ HER2 } \\
\hline Negative & $277(85 \%)$ & $164(78 \%)$ & Reference & \\
\hline Positive & $48(15 \%)$ & 47 (22\%) & 1.72 & $1.07-2.76$ \\
\hline \multicolumn{5}{|l|}{ Histology } \\
\hline Ductal & $293(90 \%)$ & $194(92 \%)$ & Reference & \\
\hline Lobular/mixed/other & $32(10 \%)$ & $17(8 \%)$ & 0.99 & $0.52-1.91$ \\
\hline \multicolumn{5}{|l|}{ Stage } \\
\hline Localized & $220(68 \%)$ & $147(70 \%)$ & Reference & \\
\hline Regional & $101(31 \%)$ & $60(28 \%)$ & 0.86 & $0.57-1.29$ \\
\hline Distant & $4(1 \%)$ & $4(2 \%)$ & 1.45 & $0.34-6.21$ \\
\hline \multicolumn{5}{|l|}{ Postmenopausal cases } \\
\hline Tumor characteristic & Minimal BPE & Mild/moderate/marked BPE & $O R^{b}$ & $95 \% \mathrm{Cl}$ \\
\hline \multicolumn{5}{|c|}{ Hormone receptor status } \\
\hline Negative & $26(27 \%)$ & $30(17 \%)$ & Reference & \\
\hline Positive & 71 (73\%) & 145 (83\%) & 2.55 & $1.22-5.34$ \\
\hline \multicolumn{5}{|c|}{ Human epidermal growth factor 2} \\
\hline Negative & $83(86 \%)$ & $152(87 \%)$ & Reference & \\
\hline Positive & $14(14 \%)$ & $23(13 \%)$ & 0.89 & $0.37-2.13$ \\
\hline \multicolumn{5}{|l|}{ Histology } \\
\hline Ductal & $80(82 \%)$ & $151(86 \%)$ & Reference & \\
\hline Lobular/mixed/other & $17(18 \%)$ & $24(14 \%)$ & 0.65 & $0.30-1.43$ \\
\hline \multicolumn{5}{|l|}{ Stage } \\
\hline Localized & $76(78 \%)$ & $132(75 \%)$ & Reference & \\
\hline Regional & 19 (20\%) & $41(23 \%)$ & 0.75 & $0.36-1.53$ \\
\hline Distant & $2(2 \%)$ & $2(1 \%)$ & 0.36 & $0.04-3.17$ \\
\hline
\end{tabular}

Abbreviations: OR odds ratio, $C l$ confidence interval, ER estrogen receptor, $P R$ progesterone receptor, HER2 human epidermal growth factor 2

${ }^{a}$ Estimated for a single unaffected breast using BI-RADS (Breast Imaging - Reporting and Data System) guidelines by a single research radiologist blinded to casecontrol status, clinical characteristics, and medical history

${ }^{\mathrm{b}}$ Multivariable-adjusted odds ratio for BPE category estimated in logistic regression with additional adjustment for (heterogeneous/dense vs fatty/scattered); BMI

$\left(<25, \geq 25\right.$ and $\left.<30, \geq 30 \mathrm{~kg} / \mathrm{m}^{2}\right)$; and conditioned on matching criteria: race/ethnicity (non-Hispanic White vs other), recruitment site, and age at MRI

(5-year categories)

'Considered positive if positive for estrogen or progesterone receptors

expression of vascular endothelial growth factor [30], suggesting that BPE is a marker of increased concentrations of glandular tissue within FGT. However, significant histopathological associations were limited to premenopausal women. Therefore, the histopathologic evidence of a biological relationship between BPE and glandular tissue concentration combined with the growing epidemiological evidence of an association between BPE and breast cancer suggests that BPE is a new biomarker of breast cancer, at least for premenopausal women.
We also reported associations between BPE and tumor characteristics among cases. There are limited previous studies that have evaluated the relation between breast tumor histology and BPE. In our study, HER2-positive cancer was independently associated with higher BPE in the unaffected breast among premenopausal cases. To our knowledge, no studies have identified a positive association between HER2-overexpression and BPE in the unaffected breast, although at least one has reported an association between triple-negative breast cancer and increased BPE [31]. We also found that the hormone 
Table 5 Summary of existing studies reporting associations between background parenchymal enhancement (BPE) and breast cancer

\begin{tabular}{|c|c|c|c|c|c|c|c|}
\hline \multirow[t]{2}{*}{ Author } & \multirow{2}{*}{$\begin{array}{l}\text { Number } \\
\text { of breast cancer cases }\end{array}$} & \multirow{2}{*}{$\begin{array}{l}\text { Number of comparison } \\
\text { women }\end{array}$} & \multicolumn{2}{|c|}{ MRI assessment methods } & \multicolumn{3}{|c|}{ Association between BPE and breast cancer } \\
\hline & & & $\begin{array}{l}\text { Blind to } \\
\text { clinical data }\end{array}$ & $\begin{array}{l}\text { Blind to } \\
\text { affected breast }\end{array}$ & $\begin{array}{l}\text { Pre- } \\
\text { menopausal }\end{array}$ & $\begin{array}{l}\text { Post- } \\
\text { menopausal }\end{array}$ & Overall \\
\hline $\begin{array}{l}\text { Arasu }^{a} \\
\text { et al. }[16 \text {, } \\
29]\end{array}$ & $\begin{array}{l}129 \text { (invasive) } \\
47 \text { (DCIS) }\end{array}$ & 4071 (cancer-free) & No & $\mathrm{N} / \mathrm{A}^{\mathrm{a}}$ & $\begin{array}{l}\text { HR } 3.0^{\mathrm{b}}(1.3- \\
7.1)\end{array}$ & $\begin{array}{l}\text { HR } 2.6^{\mathrm{b}} \text { (1.4- } \\
4.6)\end{array}$ & HR $2.3^{b}(1.5-3.4)$ \\
\hline $\begin{array}{l}\text { Grimm } \\
\text { et al. [17] }\end{array}$ & $\begin{array}{l}43 \text { (invasive) } \\
18 \text { (DCIS) }\end{array}$ & 122 (cancer-free) & Yes & No & & & OR $2.5^{\mathrm{b}}(1.3-4.8)$ \\
\hline $\begin{array}{l}\text { Melsaether } \\
\text { et al. [20] }\end{array}$ & $\begin{array}{l}81 \text { (invasive) } \\
35 \text { (DCIS) }\end{array}$ & 116 (cancer-free) & Yes & No & & & $\begin{array}{l}2 \text { readers at } 3 \text { time } \\
\text { points (range: OR } \\
1.0 \text { to } 7.7 \text { ) e }\end{array}$ \\
\hline $\begin{array}{l}\text { Bennani- } \\
\text { Baiti et al. } \\
{[18]}\end{array}$ & 353 (invasive) & 187 (benign) & Yes & No & & & OR $1.2^{d}(0.5-3.3)$ \\
\hline $\begin{array}{l}\text { Telegrafo } \\
\text { et al. [19] }\end{array}$ & 78 (invasive) & $\begin{array}{l}52 \text { (benign) } 50 \\
\text { (negative) }\end{array}$ & Yes & No & & & \\
\hline $\begin{array}{l}\text { Dontchos } \\
\text { et al. }\end{array}$ & $\begin{array}{l}12 \text { (invasive) } \\
11 \text { (DCIS) }\end{array}$ & 23 (cancer-free) & Yes & No & & & OR $9.0^{\mathrm{b}}(1.1-71.0)$ \\
\hline $\begin{array}{l}\text { Albert } \\
\text { et al. [21] }\end{array}$ & $\begin{array}{l}294 \text { (invasive) } \\
104 \text { (in situ) }\end{array}$ & 72 (cancer-free) & Yes & No & f & f & \\
\hline $\begin{array}{l}\text { King et al. } \\
{[14]}\end{array}$ & $\begin{array}{l}25 \text { (invasive) } \\
14 \text { (DCIS) }\end{array}$ & 78 (cancer-free) & No & No & $\begin{array}{l}\text { OR } 2.2^{C}(0.4- \\
11.6)\end{array}$ & $\begin{array}{l}\text { OR } 4.1^{\mathrm{C}}(1.3- \\
13.2)\end{array}$ & OR $3.3^{\mathrm{C}}(1.3-8.3)$ \\
\hline
\end{tabular}

Abbreviations: $D C I S$ ductal carcinoma in situ, $H R$ hazards ratio, $O R$ odds ratio

${ }^{a}$ Cohort study. All others are case-control studies

${ }^{\mathrm{b}}$ Comparing mild/moderate/marked vs minimal BPE

${ }^{\mathrm{c} C o m p a r i n g ~ m o d e r a t e / m a r k e d ~ v s ~ m i n i m a l / m i l d ~ B P E ~}$

${ }^{\mathrm{d}} \mathrm{OR}$ for a 1-unit increase in BPE

${ }^{\text {e}}$ Comparing controls that later developed breast cancer $(n=9)$ to those that did not develop breast cancer (107)

${ }^{f} P$ value for age-adjusted association between BPE and breast cancer was 0.15 for premenopausal women and $<0.001$ for postmenopausal women. However,

direction of association is not given and data provided do not permit calculation of ORs

receptor status of tumors was independently associated with BPE in the unaffected breast among postmenopausal cases. Two small clinical studies previously identified univariable associations between hormone receptors and BPE $[32,33]$ while others did not identify any associations [34-36]. This study is the first to report the association in a large population of women with breast cancer using a multivariable approach, but these results should be interpreted with caution and require confirmation in future studies.

This study had a number of strengths. The IMAGINE study was designed specifically to assess the association between BPE and breast cancer for premenopausal and postmenopausal women with centralized reading of MRIs. The centralized reading of MRIs eliminated interobserver variability and improved our internal validity. We also found that our single-reader design provided good intra-observer variability, but the single-reader approach may nonetheless reduce external generalizability. High intra- and inter-observer variability of visual assessment of BPE have been reported in previous studies [37], justifying the development of fully automated, objective measures of BPE for eventual clinical implementation of BPE in risk prediction. In addition, our study radiologist was blinded to both case-control status and clinical characteristics of patients and assessed BPE only in the unaffected breast without view of the affected breast, which resulted in good intra-observer reliability consistent with previous studies [38]. Furthermore, the study included a large population of cases and unaffected controls, allowing for subgroup analysis by menopausal status and a case-only evaluation of tumor subtypes.

Nonetheless, there are limitations which should be considered. First, as the source population was women undergoing breast MRI, the control group included many "high-risk" women undergoing routine screening for breast cancer, whereas the cases primarily received MRI as part of a diagnostic workup. As a result, the control population had a greater number of women with breast cancer risk factors. With adjustment for these factors, we accounted for the differing distribution of these factors as well as their association with breast cancer, but residual confounding due to selection bias is possible. Any residual confounding would bias the association between breast cancer and BPE to the null, reducing the probability of a false-positive finding. Second, this study did not have detailed information about 
MRI acquisition, which differed somewhat among participating recruitment sites. However, all participating sites are National Cancer Institute-designated Comprehensive Cancer Centers following American College of Radiology guidelines, and the analysis of MRI series with differing acquisition settings improves clinical generalizability. Third, this study lacked power to assess the utility of BPE in specific minority racial/ethnic groups, but our sensitivity analysis showed that the results were similar overall and when limited to non-Hispanic White women.

\section{Conclusions}

We found that BPE is consistently associated with breast cancer among premenopausal women and may be associated with breast cancer among postmenopausal women. Our findings confirm results from previous high-quality studies describing this association and the results are generalizable to women undergoing breast MRI, who, at present, are primarily women at high risk of breast cancer. BPE assessed by a radiologist is still limited by intra- and inter-observer variability, which may explain the unexpected non-linear association between BPE and breast cancer found among premenopausal women. As the use of MRI increases and is adopted in more settings [39, 40], future studies are needed to (a) develop objective and reproducible measures of BPE and (b) evaluate the ability of BPE to improve risk prediction for breast cancer after accounting for known risk factors. Fully automated methods of BPE assessment would permit the implementation of reproducible risk prediction in routine clinical settings, allowing the personalization breast cancer screening recommendations to improve early detection and reduce harms associated with overscreening.

\section{Supplementary Information}

The online version contains supplementary material available at https://doi. org/10.1186/s13058-020-01375-7.

Additional file 1: Table S1. Characteristics of participants that were successfully matched to those that were not successfully matched. This table provides a comparison of the characteristics of women that were successfully matched $(N=1630)$ and those that were not successfully matched $(N=168)$. Table S2. Additional analyses of the association between background parenchymal enhancement and breast cancer in the Imaging and Epidemiology (IMAGINE) Study. This table displays the results of our additional multivariable analysis: (1) restricting to nonHispanic White women, (2) using matched conditional logistic regression restricting to women that were successfully matched, and (3) excluding women with a history of simple hysterectomy, for whom timing of menopause is unclear. The results in each of the additional analyses were not markedly different from the primary analysis.

\section{Abbreviations}

FGT: Fibroglandular tissue; MRI: Magnetic resonance imaging; BPE: Background parenchymal enhancement; BI-RADS: Breast Imaging Reporting and Data System; IMAGINE: Imaging and Epidemiology Study; DCIS: Ductal carcinoma in situ; LCIS: Lobular carcinoma in situ; BMI: Body mass index; HER2: Human epidermal growth factor 2; IQR: Interquartile range

\section{Acknowledgements}

The authors would like to thank the women who participated in the IMAG INE study and made this research possible. Funding for this study was provided by the National Cancer Institute awards R01 CA183086 and P30 CA008748.

\section{Authors' contributions}

GPW conducted the analysis and drafted the manuscript. JS assessed the magnetic resonance imaging and revised the manuscript. EAM contributed to the data collection and revised the manuscript. SSB contributed to the data collection and revised the manuscript. ARB supervised the collection of data and revised the manuscript. JDB contributed to the data collection, advised the analysis, and revised the manuscript. EFC contributed to the data collection and revised the manuscript. SPW contributed to the data collection and revised the manuscript. DK contributed to the data collection and revised the manuscript. MW contributed to data collection, provided data management, provided administrative support and revised the manuscript. SVC contributed to the data collection and revised the manuscript. $\mathrm{XL}$ provided data management and analysis. MAS contributed to the data collection and revised the manuscript. MCP acquired the funding, supervised the analysis, and revised the manuscript. JLB acquired the funding, supervised the analysis, and revised the manuscript. The authors read and approved the final manuscript.

\section{Funding}

This study was funded by the National Institutes of Health, National Cancer Institute award numbers NCI R01 CA183086 and NCI P30 CA008748.

\section{Availability of data and materials}

The datasets generated during and/or analyzed during the current study are available from the corresponding author on reasonable request.

\section{Ethics approval and consent to participate}

The IMAGINE study was approved by the Institutional Review Boards at each recruiting site: Memorial Sloan Kettering Cancer Center, Perelman School of Medicine at the University of Pennsylvania, and the Huntsman Cancer Institute, University of Utah. Each participant gave written informed consent to participate in the study.

\section{Consent for publication}

Not applicable

\section{Competing interests}

The authors declare that they have no competing interests.

\section{Author details}

${ }^{1}$ Department of Epidemiology and Biostatistics, Memorial Sloan Kettering Cancer Center, 485 Lexington Ave., Second Floor, New York, NY 10017, USA. ${ }^{2}$ Department of Radiology, Memorial Sloan Kettering Cancer Center, New York, USA. ${ }^{3}$ Huntsman Cancer Institute, University of Utah, Salt Lake City, USA ${ }^{4}$ Department of Medicine, Perelman School of Medicine at the University of Pennsylvania, Philadelphia, USA. ${ }^{5}$ Dalla Lana School of Public Health, University of Toronto, Toronto, Canada. ${ }^{6}$ Department of Radiology, Perelman School of Medicine at the University of Pennsylvania, Philadelphia, USA.

Received: 17 August 2020 Accepted: 25 November 2020

Published online: 07 December 2020

\section{References}

1. Tice JA, Bissell MCS, Miglioretti DL, Gard CC, Rauscher GH, Dabbous FM, et al. Validation of the breast cancer surveillance consortium model of breast cancer risk. Breast Cancer Res Treat. 2019;175(2):519-23.

2. Tyrer J, Duffy SW, Cuzick J. A breast cancer prediction model incorporating familial and personal risk factors. Stat Med. 2004;23(7):1111-30.

3. Lee NA, Rusinek H, Weinreb J, Chandra R, Toth H, Singer C, et al. Fatty and fibroglandular tissue volumes in the breasts of women 20-83 years old: comparison of X-ray mammography and computer-assisted MR imaging. AJR Am J Roentgenol. 1997;168(2):501-6.

4. Morris $\mathrm{E}, \mathrm{CE} C, \mathrm{CH}$ L. ACR BI-RADS ${ }^{\oplus}$ magnetic resonance imaging. In: ACR BIRADS $^{\circledR}$ Atlas, Breast Imaging Reporting and Data System. Reston: American College of Radiology; 2013. 
5. Brooks JD, Sung JS, Pike MC, Orlow I, Stanczyk FZ, Bernstein JL, et al. MR background parenchymal enhancement, breast density and serum hormones in postmenopausal women. Int J Cancer. 2018;143(4):823-30.

6. Price ER, Brooks JD, Watson EJ, Brennan SB, Comen EA, Morris EA. The impact of bilateral salpingo-oophorectomy on breast MRI background parenchymal enhancement and fibroglandular tissue. Eur Radiol. 2014;24(1): 162-8.

7. Schrading $\mathrm{S}$, Schild $\mathrm{H}$, Kuhr M, Kuhl C. Effects of tamoxifen and aromatase inhibitors on breast tissue enhancement in dynamic contrast-enhanced breast MR imaging: a longitudinal intraindividual cohort study. Radiology. 2014;271(1):45-55.

8. King V, Gu Y, Kaplan JB, Brooks JD, Pike MC, Morris EA. Impact of menopausal status on background parenchymal enhancement and fibroglandular tissue on breast MRI. Eur Radiol. 2012;22(12):2641-7.

9. Scaranelo AM, Carrillo MC, Fleming R, Jacks LM, Kulkarni SR, Crystal P. Pilot study of quantitative analysis of background enhancement on breast MR images: association with menstrual cycle and mammographic breast density. Radiology. 2013;267(3):692-700.

10. Taron J, Fleischer S, Preibsch H, Nikolaou K, Gruber I, Bahrs SJER. Background parenchymal enhancement in pregnancy-associated breast cancer: a hindrance to diagnosis? Eur Radiol. 2019:29(3):1187-93.

11. Kim YJ, Kim SH, Choi BG, Kang BJ, Kim HS, Cha ES, et al. Impact of radiotherapy on background parenchymal enhancement in breast magnetic resonance imaging. Asian Pac J Cancer Prev. 2014;15(7):2939-43.

12. King V, Kaplan J, Pike MC, Liberman L, David Dershaw D, Lee CH, et al. Impact of tamoxifen on amount of fibroglandular tissue, background parenchymal enhancement, and cysts on breast magnetic resonance imaging. Breast J. 2012;18(6):527-34

13. King V, Goldfarb SB, Brooks JD, Sung JS, Nulsen BF, Jozefara JE, et al. Effect of aromatase inhibitors on background parenchymal enhancement and amount of fibroglandular tissue at breast MR imaging. Radiology. 2012; 264(3):670-8.

14. King V, Brooks JD, Bernstein JL, Reiner AS, Pike MC, Morris EA. Background parenchymal enhancement at breast MR imaging and breast cancer risk. Radiology. 2011;260(1):50-60.

15. Dontchos BN, Rahbar H, Partridge SC, Korde LA, Lam DL, Scheel JR, et al. Are qualitative assessments of background parenchymal enhancement, amount of fibroglandular tissue on MR images, and mammographic density associated with breast cancer risk? Radiology. 2015;276(2):371-80.

16. Arasu VA, Miglioretti DL, Sprague BL, Alsheik NH, Buist DSM, Henderson LM, et al. Population-based assessment of the association between magnetic resonance imaging background parenchymal enhancement and future primary breast cancer risk. J Clin Oncol. 2019;37:Jco1800378.

17. Grimm L, Saha A, Ghate SV, Kim C, Soo MS, Yoon SC, et al. Relationship between background parenchymal enhancement on high-risk screening MRI and future breast cancer risk. Acad Radiol. 2018:26:69-75.

18. Bennani-Baiti B, Dietzel M, Baltzer PA. MRI background parenchymal enhancement is not associated with breast cancer. Plos One. 2016;11(7): e0158573.

19. Telegrafo M, Rella L, Stabile lanora AA, Angelelli G, Moschetta M. Breast MRI background parenchymal enhancement (BPE) correlates with the risk of breast cancer. Magn Reson Imaging. 2016;34(2):173-6.

20. Melsaether A, Pujara AC, Elias K, Pysarenko K, Gudi A, Dodelzon K, et al. Background parenchymal enhancement over exam time in patients with and without breast cancer. J Magn Reson Imaging. 2017;45(1):74-83.

21. Albert M, Schnabel F, Chun J, Schwartz S, Lee J, Klautau Leite AP, et al. The relationship of breast density in mammography and magnetic resonance imaging in high-risk women and women with breast cancer. Clin Imaging. 2015;39(6):987-92.

22. Dontchos BN, Rahbar H, Partridge SC, Lehman CD, DeMartini WB. Influence of menstrual cycle timing on screening breast MRI background parenchymal enhancement and diagnostic performance in premenopausal women. J Breast Imaging. 2019;1(3):205-11.

23. Lee CH, Bryce Y, Zheng J, Sung JS, Comstock CE, Moskowitz C, et al. Outcome of screening MRI in premenopausal women as a function of the week of the menstrual cycle. AJR Am J Roentgenol. 2020;214(5):1175-81.

24. Harris PA, Taylor R, Thielke R, Payne J, Gonzalez N, Conde JG. Research electronic data capture (REDCap) - a metadata-driven methodology and workflow process for providing translational research informatics support. J Biomed Inform. 2009;42(2):377-81.
25. Harris PA, Taylor R, Minor BL, Elliott V, Fernandez M, O'Neal L, et al. The REDCap consortium: building an international community of software platform partners. J Biomed Inform. 2019;95:103208.

26. Fleiss JL, Cohen J, Everitt BS. Large sample standard errors of kappa and weighted kappa. Psychol Bull. 1969;72(5):323-7.

27. Pearce N. Analysis of matched case-control studies. BMJ. 2016;352:1969.

28. Brown JC, Kontos D, Schnall MD, Wu S, Schmitz KH. The dose-response effects of aerobic exercise on body composition and breast tissue among women at high risk for breast cancer: a randomized trial. Cancer Prev Res. 2016;9(7):581-8

29. Arasu VA, Miglioretti DL, Sprague BL, Alsheik NH, Buist DSM, Henderson LM, et al. Population-based assessment of the association between magnetic resonance imaging background parenchymal enhancement and future primary breast cancer risk. J Clin Oncol. 2019;37(12):954-63.

30. Sung JS, Corben AD, Brooks JD, Edelweiss M, Keating DM, Lin C, et al. Histopathologic characteristics of background parenchymal enhancement (BPE) on breast MRI. Breast Cancer Res Treat. 2018;172(2):487-96.

31. Dilorenzo G, Telegrafo M, La Forgia D, Stabile lanora AA, Moschetta M. Breast MRI background parenchymal enhancement as an imaging bridge to molecular cancer sub-type. Eur J Radiol. 2019;113:148-52.

32. Ozturk M, Polat AV, Sullu Y, Tomak L, Polat AK. Background parenchymal enhancement and fibroglandular tissue proportion on breast MRl: correlation with hormone receptor expression and molecular subtypes of breast cancer. J Breast Health. 2017;13(1):27-33.

33. Li J, Mo Y, He B, Gao Q, Luo C, Peng C, et al. Association between MRI background parenchymal enhancement and lymphovascular invasion and estrogen receptor status in invasive breast cancer. Br J Radiol 2019;33: 20190417.

34. Kim MY, Choi N, Yang JH, Yoo YB, Park KS. Background parenchymal enhancement on breast MRI and mammographic breast density: correlation with tumour characteristics. Clin Radiol. 2015;70(7):706-10.

35. Ha R, Mango V, Al-Khalili R, Mema E, Friedlander L, Desperito E, et al. Evaluation of association between degree of background parenchymal enhancement on MRI and breast cancer subtype. Clin Imaging. 2018;51: 307-10.

36. Kim JY, Kim SH, Kim YJ, Kang BJ, An YY, Lee AW, et al. Enhancement parameters on dynamic contrast enhanced breast MRI: do they correlate with prognostic factors and subtypes of breast cancers? Magn Reson Imaging. 2015;33(1):72-80.

37. Melsaether A, McDermott M, Gupta D, Pysarenko K, Shaylor SD, Moy L. Inter- and intrareader agreement for categorization of background parenchymal enhancement at baseline and after training. Am J Roentgenol. 2014:203(1):209-15.

38. Bignotti B, Calabrese M, Signori A, Tosto S, Valdora F, Tagliafico A, et al. Background parenchymal enhancement assessment: inter- and intra-rater reliability across breast MRI sequences. Eur J Radiol. 2019;114:57-61.

39. Dogan $B E$, Scoggins $M E$, Son JB, Wei W, Candelaria R, Yang WT, et al. American College of Radiology-compliant short protocol breast MRI for high-risk breast cancer screening: a prospective feasibility study. AJR Am J Roentgenol. 2017;210(1):214-21.

40. Chhor CM, Mercado CL. Abbreviated MRI protocols: wave of the future for breast cancer screening. AJR Am J Roentgenol. 2016;208(2):284-9.

\section{Publisher's Note}

Springer Nature remains neutral with regard to jurisdictional claims in published maps and institutional affiliations.

Ready to submit your research? Choose BMC and benefit from:

- fast, convenient online submission

- thorough peer review by experienced researchers in your field

- rapid publication on acceptance

- support for research data, including large and complex data types

- gold Open Access which fosters wider collaboration and increased citations

- maximum visibility for your research: over $100 \mathrm{M}$ website views per year

At $\mathrm{BMC}$, research is always in progress.

Learn more biomedcentral.com/submissions 